\title{
Using the 3D Virtual Environments for Teaching: Report from the Field
}

\author{
Maja Pivec \\ FH JOANNEUM University of Applied Sciences, Information Design, 8020 Graz, Austria, Maja.Pivec@ @ fh-joanneum.at
}

\begin{abstract}
Virtual worlds represent a powerful media for instruction, offering a wide scope of tools for social interaction and innovation in learning that encourages student participation. Supported by the AVATAR course, teachers were able to productively create teaching and learning environments that support the needs of learners of diverse linguistic, cultural and economic backgrounds, all within a safe virtual environment. This paper outlines the AVATAR course structure, delivery, experiences, and post course reflections on teaching within a 3D virtual world.
\end{abstract}

Key words: e-learning, 3D virtual environment, course structure, experience

\section{Introduction}

Despite being in the age of computers, the use of Information and Communication Technology (ICT) in teaching is still lacking, and this has become a predominant issue in secondary schools throughout Europe and around the world. Even with the educational benefits and social learning opportunities that ICT promotes, the application of computing, and more specifically digital game activities, are mostly introduced by individual teachers and related to their increased efforts in preparing lessons. Magnussen, (2007) argues that game like activities are highly engaging for the students, but the role of the teacher as facilitator is paramount to the success of the learning outcomes. Pivec and Pivec (2011) further emphasize that the advantages of using digital games and innovative ways of teaching can only be realized if the games and game like activities are designed correctly, are used in the appropriate environment, and employ a suitable pedagogical framework.

Research results from many European funded projects suggest that either video games or the interactive environment that they create can enhance the learning process (AVALON, ENGAGE 2012, Games in Schools 2012, IMAGINE 2010, MUVEnation). Digital games, Virtual Worlds, and their appropriate use for education vary considerably. Commercial educational games such as Ludwig, physics adventure game, have the quality of recreational games and include defined learning outcomes. These games employ an interface very similar to the popular commercial adventure game "Myst" from the game publisher UbiSoft (2007), and provide an interactive storyline that transports the player into a virtual world of fantasy and creates an immersive environment. Reese (2007) suggests that these virtual worlds have the potential to create player immersion (Pivec \& Pivec, 2007) and cites the concept of flow from Czikszentmihalyi (1990). Reese advocates that virtual worlds should be used as an alternate space for learning because of this immersive quality.

However, the uptake of this technology in the classroom has been slow with the major barriers being a lack of knowledge by the teacher in how to use the resource, a lack of time to prepare in adapting the game for the curriculum, and a lack of adequate technology, as outlined in Pivec (2011). Educators and especially teachers, are trained in traditional methods of delivering lesson plans that do not usually include the use of digital games and interactive technology in the curriculum. They cannot be expected to know how to integrate digital games or other 3D virtual worlds into their lessons to achieve the desired learning outcomes.

The AVATAR project (2011) was aimed at enhancing the level of ICT use in education and provided teachers with relatively new methodological and pedagogical tools. In the early stage of the project, research and comparative analysis on existing virtual world platforms were conducted, assessing the quality of teaching/learning features and functions, as well as compiling best practice cases and interviews with experts. Subsequently, a course on teaching and learning in virtual worlds was designed and piloted in-world with approximately 120 secondary school teachers from $6 \mathrm{EU}$ countries. It was offered to teachers from secondary schools in Austria, Bulgaria, Denmark, Italy, Spain and the United Kingdom. The course and related activities were developed to increase the

Received: $14^{\text {th }}$ December 2011; revised $28^{\text {th }}$ February 2012; accepted $9^{\text {th }}$ March 2012 
motivation of teachers (and students) by creating interdisciplinary and international network of teachers developing and exchanging teaching material and practice, thus improving the quality of teaching.

The pedagogical perspective of the course was built around self-directed learning and tutorials, in combination with group activities in e-learning and activities in a 3D virtual world (v-learning) environment. Activities were designed to facilitate informal and formal learning, encouraging participants to reflect on their own learning experiences, sharing their findings with the international community of teachers, and enabling them to set and pursue personal learning goals. The practical work made it possible to explore virtual worlds and gain first-hand knowledge of their potentials and pitfalls.

Quantitative and qualitative evaluation methods were applied during and after the course. During the course, an ongoing evaluation of module contents was carried out by means of feedback questionnaires and self-reflection phase at the end of each module. With the aim to gather more detailed information on didactic methodology, quality of content, and users satisfaction, an online post course survey was carried out. In addition, national focus groups and user interviews were conducted to get more detailed information as well as to explore the transferability of the AVATAR course to other segments of formal or informal learning.

In the next chapter, the AVATAR course structure, aims, learning objectives, timeline, and method of delivery are outlined. In the last chapter of this paper, a collection of post course reflections on teaching within a $3 \mathrm{D}$ virtual world outlines the appropriateness of such an environment for teaching and added value for the learning experience. With the intention to highlight some doubts and challenges that course participants were facing, interview excerpts are also included in the paper. The paper concludes outlining the success factors for teaching within virtual worlds.

\section{AVATAR course}

The course offered support for teachers integrating ICT based pedagogy and included approximately 100 hours of learning activities broken down into group activities, individual study, planning and carrying out the project work with students. The course was delivered through both an e-Learning and a $\mathrm{v}$-Learning platform comprising of a mix of tutorials, individual and group activities, and practical tasks. The 3D virtual world of Second Life (SL) was used for the course delivery for the participating teachers. National groups of teachers were moderated by national moderators (virtual world experts), who communicated in their native languages. Participants also partook in transnational activities and reflection in English.

During the four months, the course covered educational design of virtual world teaching, the management and construction of virtual objects, and learning environments and examples of learning activities within virtual worlds. During this time, teachers developed project work and used it directly in the classroom with their students. The project work incorporated a practical application of knowledge and skills gained during the course with regards to the creation of a virtual world learning environment and learning activities for a specific subject.

The overall learning objectives of the AVATAR course were for the participants to:

- develop skills and confidence in using various social internet resources as well as massively multi-user online worlds such as Second Life

- develop a deeper understanding of these environments and their uses with regard to learning scenarios

- gain knowledge of teaching methods, best practices and educational design usable in virtual worlds

- identify and reflect upon the efficacy of the outcomes of different learning activities carried out in-world

- design strategies, activities and resources for learning different subjects in virtual worlds

- integrate virtual worlds as an innovative means in their daily teaching

- experience virtual worlds with their students

- evaluate the educational use of virtual worlds in their classrooms

To achieve these objectives, the course was offered in nine modules with activities as follows:

Module 1 Introduction Module; Access to the E-learning platform and course overview

Module 2 E-Learning Platform Introduction Module; Socialisation and getting to know the functions of the E-learning platform

Module 3 V-Learning Platform Introduction Module; Accessing Second Life, acquiring basic skills, accessing Second Life support resources

Module 4 V-Learning Intermediate Module; Search for resources, building groups and communication in Second Life

Module 5 V-learning Advanced Module; Basics of object creation in Second Life

Module 6 V-Learning Advanced Module; Advanced course for object creation in Second Life

Module 7 V-Learning Educational Design Module; Introduction to different teaching methods in Virtual Worlds

Module 8 Ongoing V-Learning Seminar; Discussion with experts on different teaching methods in Virtual Worlds

Module 9 V-Learning Project Work; Designing and piloting a lesson plan with class of students

As depicted in the Figure 1, in the timetable of the course each of the modules 1-6 lasted for one week, during this week the participants were expected to spend about 5 hours per module. Modules 7 and 8 run for five weeks, in parallel to modules $3-6$. There was one activity per week and per module planned, in total 5 activities per module. Participants were expected to invest 3 hours per week to accomplish one activity, i.e. 6 hours per week for activities of both modules.

The delivery form of these modules was based on knowledge exchange and sharing experiences via e-learning and $\mathrm{v}$-learning platforms, in a mix of provided resources, invited presentations of use cases, and discussions. Resources encompassed several book titles, uploaded articles and web-articles, 


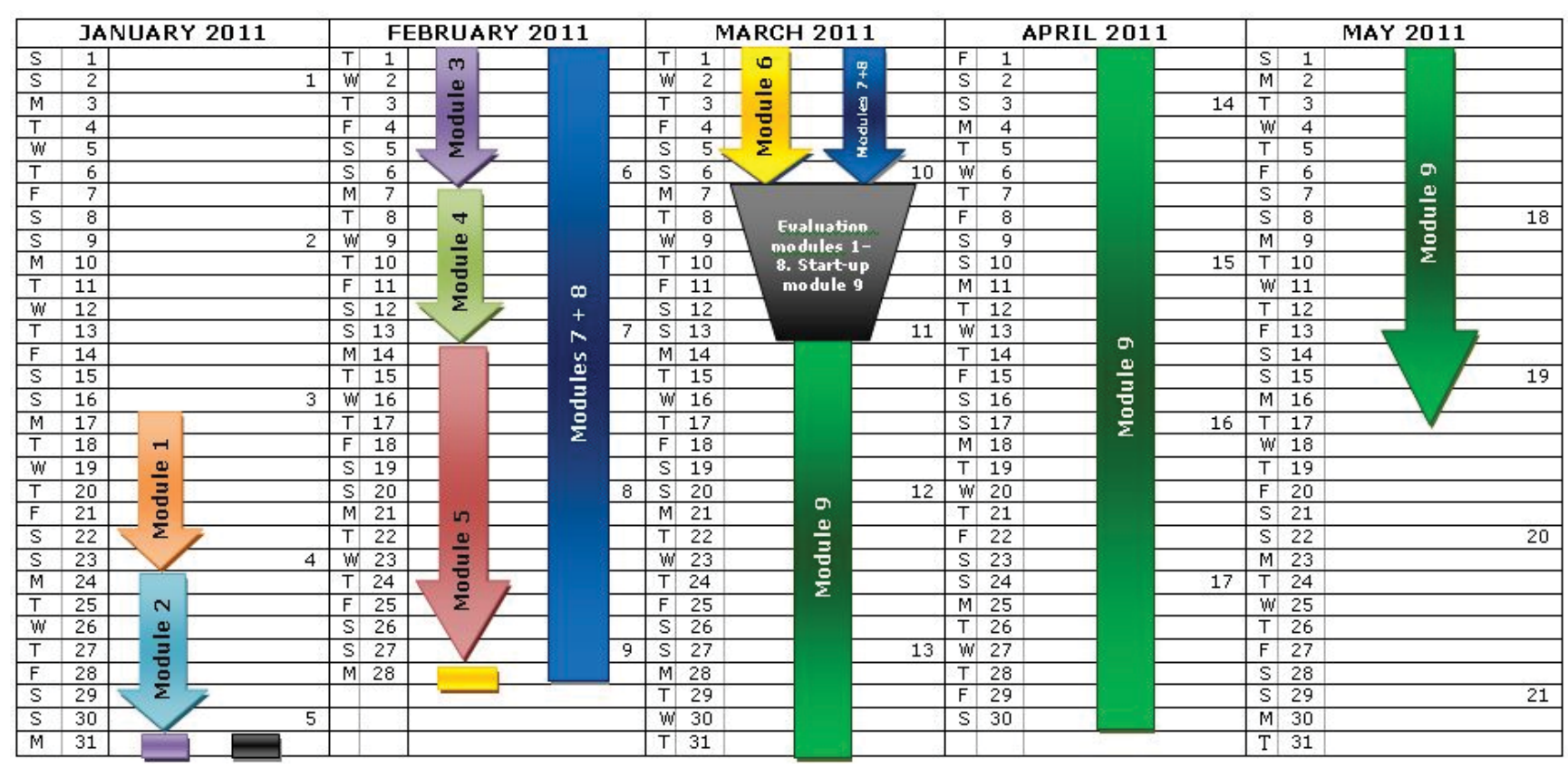

Figure 1: Timetable of the AVATAR course

guides for teaching in SL (Second Life), videos and links covering teaching practices in different disciplines using SL, from science, art, history to demonstrations of physical phenomenon, museum exhibitions, to language learning. Within SL there was an AVATAR estate Retrieved, offering quick start guides in several languages, science and art guided tours in SL, two theaters for exchange of experience and socializing, "shopping alley" with smorgasbord of building resources, and sand box estates for teachers to prepare their classes.

The aim of modules 7 and 8 was to provide more understanding of what Virtual Worlds and Massively Multiuser Online Games and worlds are, and how they are used for teaching and learning. The focus was in particular on Second Life, its culture and how it has and can be used in educational contexts.

As part of the activities of Module 8, there were three synchronous sessions with experts carried out within SL. The sessions were in form of presentations of good practice, which ended with a guided field trip exploring teaching resources. During the first session an expert from Denmark provided hints and basic building skills on how to create your own learning objects and environments for teaching English. The second session was guided by an Austrian expert on language learning in SL, followed by another Danish expert who named her session "Making history come alive".

Although the Module 8 was optional, 20 - 25 teachers participated at each of the sessions. Some of the sessions were also recorded and videos were uploaded to the forum as a resource. SL sessions with experts were very well accepted and provided an ideal opportunity to benefit from more experienced users, to get ideas and practical instructions of what works, and to ask for advice related to one's own ideas. Some resources that were demonstrated at these sessions were later incorporated by participants when creating their own lessons, e.g. using the Robin Hood Quest which is available in Second Life at the British Council Isle, as part of SL activities in the subject of teaching English as the second language. See Pivec et al. (2011) for more details on the practical work with students and their results.

Module 9 V-Learning Project Work was carried out during the last two months of the course. The purpose of the project work was to support teachers in designing their virtual world course or lesson, and subsequently piloting it with their students. Teachers had to structure their ideas by filling out a template. Besides the description of class and level, subject and learning goals, they had to consider how many students they plan to have within the class, the technical requirements and support, as well as plan for v-objects and other resources they might need. Teachers shared their plans with other participants in the forum, where other colleagues commented on their ideas and helped with hints on tools that they had discovered.

\section{Reports from the field}

After the end of the AVATAR course, an online survey on didactic methodology, quality of content, and user's satisfaction was carried out by an independent external evaluator, as outlined in the AVATAR course (2011). In total, 36 teachers responded to the post course online survey.

According to the official project figures, 123 teachers enrolled in the AVATAR course, 65 teachers attended the training, 55 dropped out and 3 acted as observers. The reasons for dropping out as stated by the course attendees via different communication channels included, i.e. personal e-mails, forum postings, module feedback questionnaires or final course survey, can be grouped into four categories: lack of interest, lack of time, technical problems, and lack of support. 
More than half of the participants answering the post course online questionnaire $(61,1 \%)$ underlined the difficulties of finding time to follow the course. Out of 65 attending teachers 26 completed the course, including carrying out the project work with their students.

Several questions were asked to evaluate why teachers would consider the application of SL for teaching. From 35 participants answering the survey, $82 \%$ shared the opinion that SL is an appropriate environment for teaching, and state:

- SL is an appropriate training environment, because it provides quick and easy access to different places and events which in real life can hardly be seen or visited.

- SL is useful if you have students who live far away and cannot come to school each day.

- It supports to learn foreign languages but the speed of the $\mathrm{PC}$ has to be efficient to enable collaboration classes from other countries.

- Part of the teaching today should also take place in virtual worlds. The young people know virtual words through their online computer gaming and can bring their competences into the learning scenario.

- Valuable teaching activities that supplement real life teaching can also take place in Second Life, especially international collaboration projects between countries.

- In the case of teaching English you have a unique opportunity to work in real time if you find collaboration partners.

- SL is the best tool for simulations; virtual tours are suitable for everything.

- SL offers an interactive way, more in line with how students interact in the modern world. Teaching in SL enables students to have the benefits of active learning.

Furthermore, many of the teachers outlined various ways of interaction that increase motivation, explorative learning, and pro-active behavior of students as added value for teaching in Second Life. Some of these explanatory statements are:

- Using SL as a teaching method makes learning easier and fun for students. It improves communication skills as well as negotiation skills of the participants/students.

- The interactivity offered in SL is a new way of teaching. You can visit or view places far away or impossible to visit.

- Looking for other ways to make my teaching subject more exciting to students.

- Teaching in SL gives better visualization of the subject for better understanding of the matter.

- It gives the opportunity to engage in a new way of learning. It increases the motivation and interest for the subject.

- Via their avatar the students become more liberated especially in language teaching, they dare to do more without feeling exposed.

- Students can act by themselves and solve problems in groups more easily than in face-to-face teaching.

- It provides an environment where students can play, cooperate, help each other and meet with students from other countries.
- They can see the world, fly, play music, perform, change appearance, have fun and forget that they are actually learning new skills, and English by participating.

- The possibility to integrate the real life teaching with activities which aren't always possible in a traditional lesson, i.e. virtual travels in distant places, experiments, meeting and talking to native people etc.

- The added value is related to the way students can improve their competences in the use of ICT tools and in the foreign language. (This is true for my project work. Students can improve their competences in many other subjects, obviously.)

However, eighteen percent of surveyed teachers disagreed, and further explained why they do not consider SL as appropriate teaching environment: These statements were:

- Maybe in some teaching subjects like architecture SL is useful, but not in general.

- It takes too much time to establish the environment.

- It is one of the possible ways but it is not "exhaustive", i.e. not all can be done in, it does not cover everything.

- You can hide your person - teaching needs personal contact.

- It is too complicated and school ICT is too slow to cope with it.

Parallel to the online post course survey and to collect more in-depth feedback on the course, focus groups and interviews with participating teachers were carried out in each partner country. Findings from these focus groups are presented in form of factors to success for teaching in the virtual worlds, are tabled at the end of this chapter. In addition, a personal reflection on the course experience and observations from piloting phase from an Austrian teacher of mathematics in the secondary school is enclosed as an individual case study. This teacher was very pro-active and had a high personal motivation and interest in teaching with technology.

Which were the most surprising aspects of the Avatar course?

That the other people that I met in-world were very supportive and trough Second Life (SL) I found a lot of mathematicians in America - there was active exchange and support from them for my problems and class experiment design.

One pupil from my group, otherwise performing rather poorly, really profited from the course. He resolved all the tasks without any help and performed in the test for couple of grades better.

Which were the most disappointing aspects of the Avatar course?

That the participating teachers in the AVATAR course were not establishing projects together (on international bases)! Several times I contacted other teachers teaching similar subjects, but there was no response.

Did you do anything differently as a result of the course? 
When teaching in SL one needs to teach differently. The pupils can actively experiment and experience things - that is the bases of the teaching approach in SL.

Did you develop new interests as a result of the course?

At the beginning I was very skeptical regarding the SL (has often bad image and bad publicity with topics as children porno, marketing...), but the experience of the SL was positive, there are a lot of possibilities what one can do there. One of the American professors has developed in Open Sim classes for math and invited me also to co-use the facilities.

However in Europe the distances are not such a problem, therefore people are mainly at campuses and sitting in the classrooms together, and do not recognize or see the advantages of using SL for learning.

After the project work with students, teachers from the AVATAR course outlined several factors to success for teaching in the virtual worlds. These practical advices can be further expanded by activities and hints how to manage various situations, catalogued in the Design Patterns for Teaching in Virtual Worlds (MUVENATION, 2011).

- Introduce the students to netiquette, so that they can interact with other avatars in the virtual world without causing offence.

- Support the students in-world by offering note cards with SLURLs, instructions etc.

- Provide a framework of modules that explain the task and related completion deadlines.

- Ask a colleague to help you with the students at the beginning of the in-world lessons, e.g. to give them support and guidance in case of technical problems or difficulties to find the class location, so you can focus on planed activities.

- Virtual worlds add an international dimension to language teaching as well as they provide interaction that motivates students to learn foreign languages.

- The AVATAR course proved to be virtual competence development for the participating teachers.

- Inform colleagues (teachers) and your didactic manager of the activities that you will carry out in-world; they will contribute to motivating the students.

- Involve the technical staff in your school at an early stage of your project, they will help you with all the technical problems (open Firewalls, install Viewer, etc).

- Valorize the work of your students.

\section{Conclusions}

Based on course results and collected feedback, the AVATAR course was well accepted by teachers and helped them to introduce new practices in their teaching. Teachers appreciated the on-line support by national moderators as well as discussions within international forums. Furthermore, the provided video tutorials on how to build in SL, textures and building blocs, and SL (Second Life) expert help were very important to overcome personal and technical barriers at the beginning of the course. Novice users of SL needed a lot of time for first steps and to practice basics. Participation in the SL part of the course required good equipment and a good Internet connection to be provided by the institutions.

Teachers reported on higher motivation and involvement of students due to the virtual classes, often taking the initiative and even volunteering to support their colleagues or create parts of practical lessons. In several cases students used the competences acquired in SL at other school projects to create added value thus achieving better results.

SL as learning and teaching environment can be also applied in other areas e.g. higher education students can access many available resources for exploratory learning with age limitations. Due to in-world the interactions with avatars, SL is very appropriate for learning communication skills and practicing languages. In general SL can motivate people to socialize, speak other languages, explore historic sites - it can be very inspiring in many different areas.

\section{Acknowledgment}

The AVATAR "Added Value of teAching in a virTuAl woRld" project was funded in the framework of the Lifelong Learning Programme - Comenius, Project Number - 502882-LLP-1-2009-1-IT-COMENIUS-CMP

\section{References}

AVALON Project. Retrieved $29^{\text {th }}$ of February 2012, from http:// avalonlearning.eu/

AVATAR course (2011). Evaluation Report On Didactic Methodology, Quality Of Content And Users Satisfaction, elaborated by Ana María García Femenía, July 2011

AVATAR project (2011). Retrieved 26th of April, 2011, from http:// www.avatarproject.eu

Csikszentmihalyi, M. (1990). Flow: The psychology of optimal experience. New York: Harper and Row.

ENGAGE (2012) European Network for Growing Activity in Gamebased learning in Education. Retrieved $29^{\text {th }}$ of February 2012, from http://www.engagelearning.eu/

Games for Learning Recommendations from IMAGINE Project (2010). ). Retrieved $29^{\text {th }}$ of February 2012, from http://games. eun.org/2010/11/games_for_learning_recommendat.html .

Games in Schools (2012), coordinated by European School Net. Retrieved $29^{\text {th }}$ of February 2012, from http://games.eun.org/

IMAGINE project (2008-2010) Increasing Mainstreaming of Games in Learning Policies. Retrieved $29^{\text {th }}$ of February 2012, from http://seriousgamesmarket.blogspot.com/2009/11/imaginemainstreaming-serious-games-for.html

Ludwig - physics adventure game. Retrieved $29^{\text {th }}$ of February 2012, from http://www.playludwig.com/en

Magnussen, R. (2007). Teacher roles in learning games - When games become situated in schools. Digital Games Research Association 2007 Conference: Situated Play, Tokyo, pp. 610 - 615.

MUVENATION Design Patterns for Teaching in Virtual Worlds. Retrieved $26^{\text {th }}$ of April, 2011, from http://muvenation.org/ pedagogical-patterns-for-virtual-worlds/

MUVEnation Project. Retrieved $29^{\text {th }}$ of February 2012, from http:// muvenation.org/

Pivec, M. (2011). Computerspiele für den Unterricht. Pädagogische Führung (Zeitschrift für Schulleitung und Schulberatung), 22(1): 8-10. 
Pivec, P. \& Pivec, M. (2011). Digital Games: Changing Education, One Raid at a Time. Int. Journal of Game-Based Learning, 1(1): 1 - 18, DOI: 10.4018/ijgbl.2011010101

Pivec, P. \& Pivec, M. (2009). Immersed but how? That is the question, Human IT, 10(1):80-104, Retrieved $8^{\text {th }}$ of March 2012, from http://www.hb.se/bhs/ith/1-10/ppmp.pdf

Pivec, M., Stefanelli, M.C., Christensen,I.-M. F. \& Pauschenwein, J. (2011). AVATAR - The Course: Recommendations for Using 3D Virtual Environments for Teaching. eLearning Papers - GameBased Learning: new practices, new classrooms, No. 25, July 2011, Retrieved $8^{\text {th }}$ of March 2012, from ht tp://ww w elearningpapers.eu/en/article/AVATAR-\%E2\%80\%93-TheCourse\%3A-Recommendations-for-Using-3D-VirtualEnvironments-for-Teaching?paper $=107280$

Reese, D. (2007). First Steps and Beyond: Serious Games as Preparation for Future Learning, Journal of Educational Multimedia and Hypermedia, 16(3), 283-300.
Ubisoft (2007). Ubisoft Corporation. Retrieved $1^{\text {st }}$ October 2007, from http://www.ubi.com

Maja Pivec is Professor of Game Based Learning and Learning with Multimedia at the University of Applied Sciences in Graz, Austria. For her research achievements Maja Pivec received the Herta Firnberg Award in the field of computer science and was awarded by European Science Foundation for an interdisciplinary workshop in the field of affective and emotional aspects of human-computer interaction, with emphasis on game-based learning and innovative learning approaches. She is coordinator, scientific leader or partner in several EU funded projects in gamebased learning, and a frequent publisher and editor on the subject of Game Design. 